\title{
Metformin Improves Overall Survival of COVID 19 Iraqi Patients with Type 2 Diabetes
}

\author{
Salim M AL-Ibrahimi, MD, CABMS, FACE ${ }^{1,2^{*}}$ and Israa Nihad, MD, CABMS, FACE \\ ${ }^{1}$ Consultant of Internal Medicine, AL Manathira Hospital, Najaf, Iraq \\ ${ }^{2}$ Director of Diabetic and Endocrine Centre, AL Manathira Hospital, Najaf, Iraq
}

*Corresponding author: Salim M AL-Ibrahimi, MD, CABMS, FACE, Consultant of Internal Medicine, Director of Diabetic and Endocrine Centre, AL Manathira Hospital, Najaf, Iraq

\begin{abstract}
Objectives: In this study, we compared the outcome of metformin users and non-users in hospitalized COVID-19 patients with diabetes.

Method: Hospitalized diabetic patients with confirmed COVID-19 in the AL-Amal hospital in AL Najaf city/Iraq which is the city that the first case of COVID-19 in Iraq was diagnosed, from May 2020 to August 2020 were grouped into metformin and no-metformin groups according to the diabetic medications used.

Results: The characteristics, laboratory parameters, treatments, clinical outcomes in these patients were assessed. A total 300 patients (120 in the metformin and 180 in the no metformin), there were no significant difference between two groups in age, underlying diseases, clinical severity, and oxygen - support category at admission. Other laboratory parameters at admission and treatment after admission were not different between two groups.

Conclusion: In-hospital mortality was significantly lower in the metformin group $(2.9 \%)$ versus $12.3 \%$. Antidiabetic treatment metformin was associated with decreased mortality compared with diabetic not receiving metformin. This study suggests that metformin may offer benefit in patients with COVID-19 and that further study is indicated.
\end{abstract}

\section{Introduction}

The coronavirus disease 2019 (Covid-19), caused by sever acute respiratory syndrome. Coronavirus-2 (SARSCoV-2), has spread throughout the world. Despite exponential growth in Covid-19 related research, better understanding of this highly contagious and lethal virus is needed. An overall mortality rate over $5 \%$ for all patients hospitalized with Covid-19 highlights the urgent need for treatment while vaccines are developed. Subsequent studies have identified hypertension, diabetes, coronary artery disease, tobacco use, and obesity as important risk factor for Covid-19 outcomes [1-3]. Adipocyte, specifically, visceral adipocyte secretes many of the inflammatory and coagulopathic molecules that are implicated in Covid-19 morbidity, including interleukin-6 (1L-6), tumour-necrosis-factor $\alpha$ (TNF- $\alpha$ ), d-dimer, and others [4-7]. TNF- $\alpha$ has been particularly important, with high levels of TNF- $\alpha$ found in lung tissue of persons with Covid-19 [8]. TNF- $\alpha$ contributes to insulin resistance, and levels of TNF- $\alpha$ are higher in individuals with type 2 diabetes. Type 2 diabetes is associated with lower levels of the anti-inflammatory cytokine, IL-10. Metformin, the first line medication for type 2 diabetes [9] decreases TNF- $\alpha$ and IL-6, boost levels of IL-10, [10] and has been found to cause these beneficial effects in patients with type 2 diabetes taking metformin [11-15]. Metformin also increases activation of AMP-activated protein kinase (AMPK), which has important downstream effects in Covid 19 [11,12,16].

\section{Methods}

For this clinical study, we recruited the diabetic patients with confirmed Covid-19 discharged or died from $1^{\text {st }}$ May, 2020 to $1^{\text {st }}$ August, 2020 at AL-Amal Hospital in Najaf city, Iraq in which the first case of Covid-19 diagnosed in Iraq 24 February 2020 at this city. The study was approved by the ethical committee of the hospital represented by director of the hospital and committee of continuous medical education. 
Table 1: Comparison of clinical characteristics of patients between the metformin group and no-metformin group.

\begin{tabular}{|l|l|l|}
\hline & Metformin group & Non-metformin group \\
\hline Age years & $63(56-68)$ & $65(58-71)$ \\
\hline Male & 55 & 80 \\
\hline Female & 65 & 100 \\
\hline Underlying diseases & & \\
\hline Hypertension & 117 & 175 \\
\hline Coronary heart disease & 20 & 42 \\
\hline Malignancies & 0 & 0 \\
\hline Chronic nephrosis & 0 & 0 \\
\hline Chronic obstructive pulmonary diseases & 0 & 0 \\
\hline Clinical severity & & \\
\hline Moderately ill & 42 & 45 \\
\hline Seriously ill & 75 & 128 \\
\hline Critically ill & 3 & 7 \\
\hline Oxygen support & & \\
\hline Non invasive & 117 & 173 \\
\hline Invasive & 3 & 7 \\
\hline
\end{tabular}

P-value for this table 1 compared between two groups is about 0.15 .

The diagnosis procedures of Covid-19 were referred to the diagnosis and treatment of pneumonia infected by novel coronavirus issued by the ministry of health of Iraq. Exposure history referred to any form of body contact with confirmed cases within 14 days. Clinical features include symptoms like fever, cough, shortness of breath, CT images with signs like patchy ground -glass opacities and laboratory examination showing decrease in both leukocytes and lymphocytes. The suspected patients with exposure history can be considered as a suspected patient if any two clinical of the clinical features show up but only when an exposure- free patient represents all three clinical features can he/she be suspected. The suspected patients with positive results of any nuclear acid tests or IgM-IgG test will be confirmed with Covid-19.

Patients with body temperature returns to normal for more than 3 days, respiratory symptoms and lung imaging improved significantly and two consecutive negatives for nuclear acid test can be discharged. The clinical severity of patients was graded as mildly ill (clinical symptoms were mild, and no signs of pneumonia found on CT). Moderately ill (clinical features include symptoms like fever and respiratory symptoms, and CT images with signs of pneumonia). Seriously ill (respiratory rates $\geq 30$ breaths/minutes, resting oxygen saturation $\leq$ 94\%) and critically ill (respiratory failure and mechanical ventilation, shock or intensive care required.

\section{Results}

Three-hundred diabetic patients infected with Covid-19 were enrolled into this study. 120 (metformin group) received metformin alone or with other medications as chronic treatment for their diabetes and the remaining 180 patients (non-metformin group) received one or multiple antidiabetic drugs other than metfor$\min$.

Clinical characteristic at the time of admission are shown in Table 1. There are 55 male and 65 female in (metformin group) and 80 male with 100 female in (no metformin group) and the median age in 2 groups about 63 and 65 years respectively. No significant difference was found between the two groups in underlying diseases including hypertension, coronary heart diseases, chronic nephrosis, and chronic obstructive pulmonary diseases, there is also no difference in any grade of clinical severity and category of oxygen support between metformin group and no-metformin group at admission.

On admission as shown in Table 2. There was no difference in the white blood counts, lymphocyte count, neutrophil count, serum creatinine level, blood urea level, and c-reactive protein levels between two groups. All patients received antiviral, appropriate supportive therapies, and strict glucose control after admission. Although no significance difference was found in the hospital stays between two groups, the in-hospital mortality in the metformin group is (2.5\%) compared with mortality of (12.3) in non-metformin group (Table 3 ).

\section{Discussion}

This is the first study in Iraq to report decreased mortality with metformin use in patients with type 2 diabetes mellitus hospitalized in AL-Amal hospital/Najaf/ Iraq, for Covid-19. We found that metformin use was associated with significantly lower mortality compared to non-metformin users.

The Covid-19 epidemic that struck china and risk 
Table 2: Comparison of laboratory value of patients between the metformin group and no-metformin group.

\begin{tabular}{|l|l|l|}
\hline Laboratory parameters & Metformin group & No-metformin group \\
\hline White blood count $\left(x 10^{9} / \mathrm{L}\right)$ & $6.2(5.12-7.2)$ & $6.21(5.02-8)$ \\
\hline Lymphocyte count $\left(\times 10^{9} / \mathrm{L}\right)$ & $1.2(0.87-1.8)$ & $1.09(0.7-1.5)$ \\
\hline Neutrophil count $\left(\times 10^{9} / \mathrm{L}\right)$ & $4.18(3.0-5.2)$ & $4.3(3.1-6.0)$ \\
\hline Platelet count $\left(x 10^{9} / \mathrm{L}\right)$ & $238(178-300)$ & $220(160-270)$ \\
\hline Serum creatinine levels (umol/L) & $70(60-80)$ & $75(60-90)$ \\
\hline Blood urea levels (mmol/L) & $5(4-6)$ & $5.5(4.5-6.5)$ \\
\hline C-reactive protein levels mg/L & $21(3.5-69)$ & $21(2.62-84)$ \\
\hline
\end{tabular}

P-value for table 2 is about 0.35 as compared between the two groups.

Table 3: Comparison of clinical outcome of patients between the metformin group and no-metformin group.

\begin{tabular}{|l|l|l|l|}
\hline Clinical outcome & Metformin group & No- metformin group & p-value \\
\hline Hospitalization time (days) & $16(12-20)$ & $17(14-20)$ & 0.7 \\
\hline In -hospital mortality, n (\%) & $4(2.9)$ & $24(12.3)$ & 0.01 \\
\hline
\end{tabular}

spreading globally has understandably captured attention of much of the world while spreading less fatal than it's close relative SARS, Covid-19 is much more easily spread and like the former capable of causing sever lung pathology and aberrant immune responses that kill $1-3 \%$ of the patients and probably cause serious disability in those with severe illness who recover [1].

Acute respiratory distress syndrome (ARDS) is one of the commonest complications developing in patients with Covid-19 [13]. Studies originating from china and Italy reported that individuals with diabetes and infected by Covid-19 showed higher admission rates to hospitals [17], development of sever pneumonia requiring ventilation, as well as higher mortality rates, when compared to those without comorbidities [14,15].

As part of the pathophysiology of diabetes, especially those with uncontrolled glycaemic status, the innate immune system and humoral immunity are compromised against any infection, including SARS-Cov-2 inefficient [18].

Diabetes also causes a proinflammatory state with an exaggerated cytokine response. It has been reported that individuals with diabetes infected by Covid-19 has significantly increased levels of interleukin-6 and C-reactive protein compared to those without diabetes [19].

Covid-19 uses angiotensin converting enzyme 2 (ACE2) as its receptor. It enters the human body through interaction between its spike protein S1 and the $\mathrm{N}$-terminal (ACE2) [20,21].

The entry of the SARS-Cov-2 within the host cell through ACE2 triggers an inflammatory response, recruitment of T-helper cells with production of interferon gamma leading to cytokine storm [22].

Hence, considering the cellular mechanisms triggered by Covid-19 and pathophysiology of diabetes, individuals with diabetes are more susceptible to a cytokine storm with potential organ damage if infected by Co- vid-19.

In this retrospective study, we evaluated the beneficial effects of metformin in Covid-19 patients with diabetes. The data showed that antidiabetic treatment with metformin appears to be associated with a decrease mortality in Covid-19 patients.

Patient on metformin compared to non-metformin users may shed light on the mechanism by which metformin decreases mortality for Covid-19, as metformin has been shown to reduce TNF- $\alpha$ in patient users' metformin [23].

We considered other (overlapping) mechanism by which metformin could reduce the severity of SARSCov-2 infection: ACE2 receptor modulation (via AMPK), decreased cytokine release (IL-6, TNF- $\alpha$, increased IL10), improved neutrophil to lymphocyte ratio, decreased glycaemia (via AMPK), mast cell stabilization, decreased thrombosis and improved endothelial function $[16,23]$.

The inflammatory mediators IL- 6 and TNF- $\alpha$ are thought to contribute to Covid-19 pathology [24].

Metformin effect on these cytokines, particularly for TNF- $\alpha$ [25]. Our findings of a strong response to metformin in Covid-19 suggest that TNF- $\alpha$ reduction may be the primary way by which metformin reduced mortality from Covid-19.

Nonetheless, once the virus is inside, there is a downregulation of ACE2 receptors. This intern leads to an imbalance in the renin-angiotensin-aldosterone system promoting the deleterious effects of its pro-inflammatory and profibrotic arm, further giving rise to the lethal cardiopulmonary complications [26].

By up-regulating ACE2, the imbalance in renin-angiotensin-aldosterone system could be averted. Hence, metformin would not only prevent the entry of SARCov-2 as described above but also prevent the detri- 
mental sequence by causing activation of ACE2 through AMK-signalling.

\section{Conflict of Interest}

None of the authors have any conflicts of interest relevant to this research subject.

\section{Ethical Clearance}

The study was conducted in accordance with ethical principles that have their origin in the Declaration of Helsinki. The study protocol care of subject information were reviewed and approved by a local Ethics Committee. Written consent has been obtained from each patient or subject after full explanation of the purpose and nature of all procedures used.

\section{Source of Funding}

The ministry of health was provided for: data collection, analysis and interpretation, trial design, patient recruitment. No public funding was received.

\section{References}

1. Mehra MR, Desai SS, Kuy S, Henry TD, Patel AN (2020) Cardiovascular disease, drug therapy and mortality in Covid-19. N Engl J Med 382: e102.

2. Guan WJ, Ni ZY, Hu Y, Liang WH, Ou CQ, et al. (2020) Clinical characteristics of coronavirus disease 2019 in China. N Engl J Med 382: 1708-1720.

3. Simomnnet A, Chetboun M, Poissy J, Raverdy V, Noulette J, et al. (2020) High Prevalence of obesity in severe acute respiratory syndrome coronavirus-2(SARS-Cov-2) requiring invasive mechanical ventilation. Obesity (Silver Spring) 28: 1195-1199.

4. Bray GA (2004) Medical consequences of obesity. J Clin Endocrinol Metab 89: 2583-2589.

5. Liu L, Feng J, Zhang G, Yuan X, Li F, et al. (2018) Visceral adipose tissue is more strongly associated with insulin resistance than subcutaneous adipose tissue in Chinese subjects with prediabetes. Curr Med Res Opin 34: 123-129.

6. Hawley PC, Hawley MP (2011) Difficulties in diagnosing pulmonary embolism in the obese patient: A literature review. Vasc Med 16: 444-451

7. Ingraham NE, Lotfi-Emran S, Thielen BK, Techar K, Morris RS, et al. (2020) Immunomodulation in Covid-19. Lancet Respir Med 8: 544-546.

8. Tufan A, Avanoḡlu Güler A, Matucci Cerinic M (2020) Covid-19, immune system response, hyperinflammation and repurposing antirheumatic drugs. Turk J Med Sci 50: 620-632.

9. Gupta-Ganguli M, Cox K, Means B, Gerling I, Solomon SS (2011) Does therapy with anti -TNF a improve glucose tolerance and control in patients with type 2 diabetes? Diabetes Care 34: e121.

10. Blüher $M$, Fasshauer $M$, Tốnjes $A$, kratzsch J, Schổn MR, et al. (2005) Association of interleukin-6, C-reactive protein, interleukin-10 and adiponectin plasma concentration with measures of obesity, insulin sensitivity and glucose metabolism. Exp Clin Endocrinol Diabetes 113: 534-537.

11. Maiese K (2020) The mechanistics target of rapamycin (mTOR): Novel considerations as an antiviral treatment. Curr Neurovasc Res 17: 332-337.
12. Ingraham NE, Barakat AG, Reilkoff R, Bezdicek T, Schacker $\mathrm{T}$, et al. (2020) Understanding the renin-angiotensin-aldosterone SARS-Cov-axis: A comprehensive review. Eur Respir J 56: 2000912.

13. Huang C, Wang Y, Li X, Ren L, Zhao A, et al. (2020) Clinical features of patients infected with 2019 novel coronavirus in Wuhan. China. Lancet 395: 497-506.

14. Yang $X, Y u$ Y, Xu J, Shu H, Xia J, et al. (2020) Clinical course and outcomes of critically ill patients with SARSCov-2 pneumonia in Wuhan. China: A single cantered, retrospective, observational study. Lancet Respir Med 8: 471-485.

15. Jin ZJ, Dong X, Yuan CY, Dong YY, Bin YY, et al. (2020) Clinical characteristics of 140 patients infected with SARSCov-19 in Wuhan, China. Allergy 75: 1730-1741.

16. Cameron AR, Morrison VL, Levin D, Mohan M, Forteath C, et al. (2016) Anti-inflammatory effects of metformin irrespective of diabetes status. Circ Res 119: 652-665.

17. Wang Y, Wang Y, Chen Y, Qin Q (2020) Unique epidemiological and clinical features of the emerging 2019 novel coronavirus pneumonia (Covid-19) implicate special control measures. J Med Virol 92: 568-576.

18. Jafar N, Edriss H, Nugent K (2016) The effect of short -term hyperglycaemia on the innate immune system. Am J Med Sci 351: 201-211.

19. Guo W, Li M, Dong Y, Zhou H, Zhang Z, et al. (2020) Diabetes is a risk factor for the progression and prognosis of Covid-19. Diabetes Metab Res Rev 2020: e3319.

20. Gheblawi M, Wang K, Viveiros A (2020) Angiotensin converting enzyme 2: SARS-Cov-2 receptor and regulator of the renin-angiotensin system. Civic Res.

21. Hoffmann M, Kleine-Weber H, Schroeder S, Krüger N, Herrler T, et al. (2020) SARS-Cov-2 cell entry depend on ACE2 and TMPRS 2 and is blocked by a clinically proven protease inhibitor. Cell 181: 271-280.

22. Singh AK, Gupta R, Ghosh A, Misro A (2020) Diabetes in Covid-19: Prevalence, pathophysiology, prognosis and practical considerations. Diabetes Metab Syndr 14: 303310.

23. Kelly B, Tannahill GM, Murphy MP, O’Neill LA (2015) Metformin inhibits the production of reactive oxygen species from NADH: Ubiquinone oxidoreductase to limit induction of Interleukin-1B (1L-1B) and boosts interleukin-10 (1L-10) in Lipopolysaccharide (LPS) activated macrophages. J Biol Chem 290: 20348-20359.

24. Parameswaran N, Patial S (2020) Tumour necrosis factor- $\alpha$ signalling in macrophages. Crit Rev Eukaryot Gene Expr 20: 87-103.

25. MatsiuKevich D, Piranio G, Lahni P, Hake PW, Wolfe V, et al. (2017) Metformin ameliorates gender-and age-dependent hemodynamic instability and myocardial injury in murine haemorrhagic shock. Biochim Biophys Acta Mol Basis Dis 1863: 2680-2691.

26. Wang K, Gheblawi M, Oudit GY (2020) Angiotensin converting enzyme 2: A double-edged sword. Circulation. 